\title{
Research on the Evolution and Upgrading Mode of Industrial Clusters From the Perspective of Sharing Economy — Countermeasures of Taiwan's Bicycle Industry
}

\author{
Xinjie Zhang ${ }^{1, *}$ Zhengkai $\mathrm{He}^{2}$
}

\author{
${ }^{1}$ Financial Affairs Office, University of Electronic Science and Technology of China, Chengdu, Sichuan, China \\ ${ }^{2}$ School of Public Affairs and Administration, University of Electronic Science and Technology of China, Chengdu, \\ China \\ *Corresponding author. Email: 731039388@qq.com
}

\begin{abstract}
A successful industrial cluster is a booster of the rapid development of regional economy and an important way to enhance national competitiveness. On the basis of practical investigation, combining the existing industrial cluster evolution model and industrial upgrading theory, this paper constructs the five-stage evolution and upgrading mode of industrial cluster, expounds the characteristics of each evolution stage, and analyzes the industrial upgrading mode from the lower stage to the higher stage. And it explains this mode in combination with the evolution history of bicycle industry cluster in Taiwan. The results show that the transformation and upgrading of Taiwan's bicycle industry cluster in the sharing economy model depends on the change of market sales model and the organization's flexible coping strategy, which allows the cluster value itself to be "shared".
\end{abstract}

Keywords: industrial cluster, evolutionary stage, sharing economy, upgrading mode

\section{INTRODUCTION}

With the deepening of globalization, the number of industrial clusters is increasing and the competition is becoming increasingly fierce. Industrial clusters tend to upgrade or decline in the ups and downs of evolution. For example, the continuous growth of the woolen sweater industry cluster in Puyuan, Zhejiang Province is in sharp contrast to the decline of the automobile industry cluster in Detroit and the lighting industry cluster in Wenzhou. It can be seen that the dynamic evolution of clusters does not necessarily lead to success. And it is the successful industrial cluster that can boost the rapid development of regional economy and is an important way to enhance national competitiveness

The bicycle industry is a labor-intensive industry. Since the formation of the bicycle industry cluster in Taiwan in the 1970s, it has been continuously transforming and upgrading to excellence. In terms of exports, unit prices and sales, it is far ahead of mainland China. The bicycle industry in mainland China is large but not strong, lacking competitiveness. The operation of bike-sharing platforms such as Mobike and Ofo in the mainland is a beneficial exploration to solve the "last kilometer" problem of urban traffic. As a result, the traditional bicycle industry has ushered in the spring, but it has caused a huge impact on Taiwan's bicycle manufacturing industry. Can the existing advantages of Taiwan's bicycle industry cluster be maintained under the challenge of sharing economy and how will the further evolution of the cluster be?

The sustainable growth of regional economy depends on the sustainable development of clusters, and the sustainable development of clusters depends on their sustainable upgrading ability. This paper combines the research of Bergman. E. M and Feser. E. J. (1999) [1] and Shao Yunfei et al. (2010) [2] on cluster evolution to build a five-stage model of industrial cluster life cycle evolution, that is, industrial clusters generally go through potential stage, emergence stage, expansion stage, maturity stage and adjustment stage.

Bike-sharing derived from the concept of sharing economy may bring a devastating blow to the traditional bicycle industry by reshuffling the industry. At present, researches on bike-sharing mainly focus on the development status, platform competition, management strategy and prospect prediction; few studies analyze the response of industrial clusters from the perspective of existing bicycle industry cluster chain manufacturers. It is timely and necessary to analyze the response of bicycle industry cluster in the adjustment stage from the perspective of sharing economy. This is conducive to the improvement of the original model of industrial cluster evolution and upgrading, contributing to the careful response of industrial clusters to various stages of the development cycle, to effectively do a good job in industrial upgrading, and to promote the sustainable development 
of clusters. It also has certain reference value to the development of bicycle industry cluster in Taiwan.

\section{THE EVOLUTION STAGES AND INDUSTRIAL UPGRADING MODE OF INDUSTRIAL CLUSTER}

The evolution of the industrial cluster from a lower stage with corresponding stage characteristics to another higher stage with corresponding stage characteristics is inseparable from the upgrading of the industry. This paper divides the evolution process of industrial cluster into potential stage, emerging stage, expansion stage, mature stage and adjustment stage. The adjustment stage faces three trends: decline, transfer and upgrade. There are risks and uncertainties in the process of the evolution of industrial clusters. Only by finding out and overcoming the existing problems of clusters at the corresponding stage can the upgrading and sustainable development of industrial clusters be promoted. This article summarizes this (see "Fig. 1") and the specific analysis of stage evolution and industrial upgrading mode is as follows:

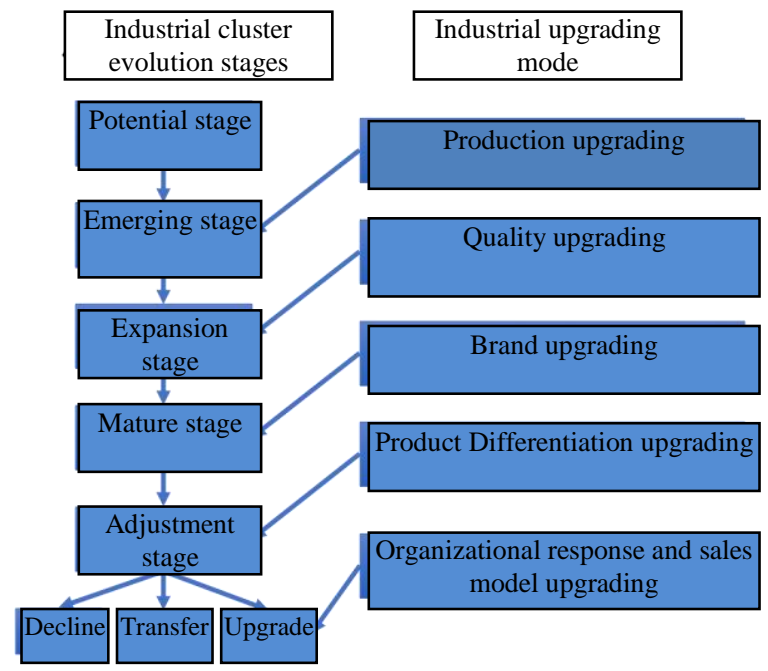

Fig. 1. Industrial cluster evolution stages and industrial upgrading mode.

\section{A. The potential and emerging stages of cluster evolution}

The potential stage of cluster refers to the possibility of cluster developing towards trend or under policy guidance. In the embryonic state, the enterprises have no advantage in number, scale and structure, and with no set standard, they scattered in the region, developing slowly. Enterprises need to imitate and copy leading enterprises to reduce risks and improve the speed of development. The whole cluster is in the initial stage, with abundant internal resources, low cost, less competition among enterprises and weak sense of cooperation. All enterprises are in a relatively independent and dispersed state, "gathering yet not united". In order to break through the potential stage to the emerging stage, the cluster needs to greatly increase the output and obtain the quantity advantage.

Cluster evolution development stage refers to that the cluster has significant performance, but has not yet reached the equivalent output, and thus does not have the scale advantage. As a large number of enterprises joined the cluster, the communication between enterprises increased, the scale increased, the sense of competition gradually formed, and the agglomeration advantage appeared. In this stage, the main goal of the enterprise is mass production, to obtain economies of scale, with serious product homogeneity Enterprises will produce large quantities of products at low cost and low price as the primary goal, and the overall quality level of the cluster is not high, so the cluster needs to improve product quality if it wants to leap from the development stage to the expansion stage.

\section{B. The expansion and maturity stage of cluster evolution}

The expansion stage refers to the period of rapid expansion of industrial clusters. Competition and cooperation among enterprises coexist, and as the density of enterprises increases, the benefit scale of clusters expands. With the improvement of technical level and product quality, enterprises can quickly seize market share by virtue of their production and quality advantages, and the competition between enterprises is fierce. Considering the advantages of low cost and scale, clusters will attract more relevant enterprises and service institutions to join. With close communication between enterprises and serious product homogeneity, it is easy to form vicious competition within the cluster and also creates milieux of innovation. The goal of the cluster is to improve the production efficiency, increase the technology research and development, establish the enterprise's own brand, form multi-class brand products in the industry, expand the market and improve the profit. Therefore, the breakthrough point of this stage lies in technology research and development and the creation of characteristic brands.

The maturity order of industrial cluster refers to the maximum scale and density within the cluster. Intragroup enterprises may change from the previous competitive situation to the coexistence of competition and collaboration, and the social network organization is developed. At the same time, it is easy for the leading products in the cluster to be imitated and surpassed, and the core toughening in the cluster reduces enterprises' willingness to innovate. In order to break the rigid state of the organization, the enterprises should seek common points while reserving difference, apply cutting-edge technology, grasp the latest trends, implement differentiated product strategy, enhance the 
added value, and strive to achieve the upgrade from brand to famous brand.

\section{The adjustment stage of cluster evolution}

After the mature stage of industrial cluster, the agglomeration effect tends to be saturated and the operating efficiency slows down. Enterprises enter the adjustment phase. Industrial maintenance, transformation and upgrading are the choices of intragroup enterprises. Different adjustment methods bring different evolution results, namely decline, transfer and upgrade. The maintenance of static industries that rely too much on the original advantages and experience will accelerate the decline of clusters and face the problems of rising prices of labor, land and raw materials and resource exhaustion. In order to seek a new way, enterprises and service organizations may choose to leave the original cluster and obtain profits through industrial transfer. However, some enterprises with a high sense of risk, can quickly identify the changes of regional comparative advantage, constantly adjust the organizational structure flexibly according to the market environment, and change the sales model. Therefore, the cluster may make a breakthrough under the guidance of this kind of enterprises and promote the evolution of the cluster to a higher level. At present, the bicycle industry cluster in Taiwan has formed a complete upper, middle and downstream combination system for middle and high-end products. However, it is uncertain whether the emerging business operation mode of sharing bicycles can flexibly adjust the organizational response and realize the upgrade.

\section{EVOLUTION OF BICYCLE INDUSTRY CLUSTER IN TAIWAN}

With a history of more than 40 years, the industrial cluster in Taiwan is known as the "kingdom of bicycles". Taiwan's bicycle industry is export-oriented, with a ratio of export to domestic sales of 9:1. The top three markets for bicycle exports are the European Union, the North American free trade area and mainland China. Taiwan's bicycle industry had been performing well up to 2015. The rapid growth of bikesharing in the Chinese mainland since 2016 has led to a sharp drop in the number of total bikes exported from Taiwan to the Chinese mainland, and a continued downturn in the mainland market (as can be seen from "Fig. 2"). Taiwan's exports of finished bicycles have also been falling because of economic volatility in Europe and U.S. politics. As bike-sharing platforms such as Mobike and Ofo enter the global market, they may threaten the market share of Taiwan's bicycle industry in the European Union and North America. Taiwan's bicycle industry cluster faces severe challenges (Source: Taiwan Trade Association of Bicycle Export website).

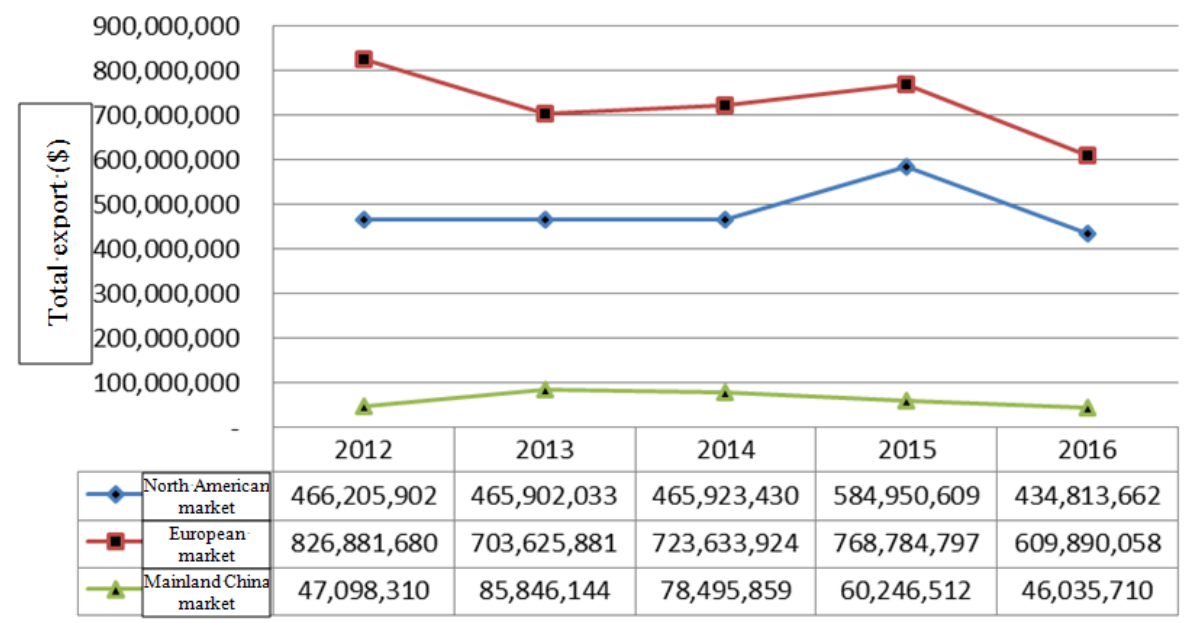

Fig. 2. Statistics on the total volume of the three major export markets of Taiwan's bicycle industry from 2012 to 2016.

According to the study of Mao Yunshi [3] (2011) and other scholars, the formation of Taiwan's bicycle industry cluster to 2015 was divided into four stages. With the emergence of bike-sharing from 2015 to 2016, the bicycle industry in Taiwan will face new challenges. Therefore, this paper summarizes the evolution of Taiwan's bicycle industry cluster into five stages: potential stage before 1970, emergence stage from 1970 to 1985, expansion stage from 1985 to 1998 , maturity stage from 1998 to 2015, and adjustment stage from 2015 to now. Combining with the industrial upgrading in the evolution of Taiwan's bicycle industry cluster, this paper focuses on the development of Giant Global Group and Merida Group, and analyzes each evolution stage in detail.

\section{A. The potential and emerging stage of bicycle industry cluster in Taiwan}

After the Second World War, Taiwan's bicycle industry began to implement local manufacturing. Under the strong support and policy guidance of the Taiwan government, 
bicycles were produced in large quantities and exported to the United States in 1967. The quantity and quality of bicycles were at a low level, and most companies pursued low prices to reduce production costs so that they could produce more. Although they produced more than 1 million bicycles in 1968, there was a risk that they would not be able to increase production and the products would be of poor quality. In 1970, when demand from overseas markets declined, Taiwan's bicycle production and export volume declined, and the low quality of the bicycles limited the quantity of exports. Therefore, the industry is in urgent need of making use of the advantages of cluster to improve production efficiency and realize the balance of bicycle output and quality. Then under the leadership of Liu Jinbiao, chairman of the Giant Global Group, the standardization of bicycle production was made clear. This played a key role in improving production efficiency and promoting the improvement of output and quality. Taiwan's bicycle industry cluster has successfully entered the emerging stage.

In 1970, the Merida Group won an order from SCHWINN, a major US bicycle maker, and Taiwan's bicycle production soared. But the problem of substandard bicycle products still plagued Taiwan's bicycle industry. The 1972 Oil Crisis in the United States brought more orders, but the "Safety Standards of CPSC" in the United States also imposed stricter quality requirements on Taiwanese bikes. Through the efforts of the enterprises in the cluster, they overcame the obstacles of poor quality and achieved a record high of 9.2 million bicycle exports in 1986. Taiwanese bicycle companies represented by Giant became large Original Equipment Manufacturers (OEM) for American buyers. They learned a lot of advanced technology and management experience, which promoted the professional division of labor between complete bike manufacturers and parts manufacturers. In 1976, Giant took "Contributing to Society with the "Highest quality and Reasonable Price" as its basic operating policy, which made the company turn from loss to profit. During this stage, Taiwan's bicycle industry cluster promoted the standardization of complete bike manufacturing and spare parts manufacturing due to knowledge accumulation, technology improvement, specialization and collaboration, and formed an open network of inlaid coordination among various enterprises, laying a foundation for the formation of the upper, middle and lower reaches of the bike industry system, with significant quality upgrading. Taiwan's bicycle industry cluster entered the expansion stage.

\section{B. The expansion and maturity of Taiwan's bicycle industry cluster}

Relying on the advantages of low cost and improved product quality, the number of OEM enterprises in Taiwan's bicycle industry was still increasing greatly and the scale of the industry was expanding. Low technology and low added value make the cluster at the bottom of the bicycle value chain with low profit. SCHWINN's withdrawal of large orders from Taiwan confirms the instability and high risk of this type of production. At this stage, Taiwan's bicycle industry cluster improved its independent research and development capability and established its own brands.

The industrial system, in which the upper, middle and lower reaches of Taiwan bicycle industry cluster composition were integrated closely promoted internal communication and exchange, enhanced mutual learning, allowing all to acquire heterogeneous resources. Enterprises represented by Giant and Merida implemented the brand building strategy at this stage and achieved good results, which promoted the overall capacity of brand building of the whole cluster. In 1985, Giant Group established the research and development alliance by cooperating with the Material Department of Taiwan's industrial institute. They made joint efforts in developing the iron fibber bikes, the sales of which topped 1 million. It was then committed to strengthening the development of new materials and new accessories for bicycles, enhancing its independent innovation ability. After the creation of Giant brand was established in 1981, in 1986 in the Netherlands giant corporation in Europe, the group built up the parent company of Giant in Europe, which pushed the brand to the international market. Subsequently, giant Australia, Canada, China and Poland co., ltd. were established successively. In this way, Giant brand began to have an international positioning and gradually lead the world, and has become one of the three major brands in the European market. Merida also carried out a forward-looking global layout. In 1987, it started marketing in Norway with its own brand "MERIDA", and successively settled in Germany, Britain and other places, promoting high-performance and diversified products to the global market and becoming one of the top 20 international brands in Taiwan. Under the leadership of the core enterprises, the brand image and status of Taiwan's bicycle industry have been recognized internationally. Brand upgrading has pushed Taiwan's bicycle industry cluster into a mature stage.

In the late 1990s, the original advantages of land, materials and labor cost changed. In order to optimize the allocation of resources, the low-value-added production of Taiwan's bicycle industry was successively transferred to the mainland. The key to the transformation is to improve the technological level, strengthen the cluster cooperation, increase the added value and profit of private brands, and carry out differentiated operation. Since 2003, Giant Group, together with its rival Merida, has formed an A-Team by allying downstream suppliers. With the assistance of the Bureau of Industry of the Ministry of Economic Affairs of Taiwan and the Corporate Synergy Development Center, they have formulated plans for industrial upgrading, such as product innovation and brand image building. It has promoted the bicycle industry in Taiwan to make a leap from quality to value and upgrade to the high end of the global value chain, strengthened the market mechanism and brand image, and effectively integrated the bicycle market.

In addition to the A-Team, giant group and Merida group have raised international brand awareness by sponsoring global events. For example, in 2013, Merida sponsored the top Italian team "Team Lampre Merida" to 
participate in the top international races, which enhanced the brand image and recognition. Giant group further refined the functions of its own three brands, making it clear that Giant focuses on sports and competitive products; liv is designed to be the most suitable bike for female consumers; and Momentum is a kind of high quality and affordable vehicle. They can effectively meet the needs of different customers, with an obvious product differentiation. In addition, the whole cluster teamed up with the government to organize bicycle carnival, bicycle year and other activities to promote the overall image of Taiwan's bicycle industry. In general, Taiwan's bicycle industry has realized its high value-added and differentiated positioning in the global value chain. After 1998, the export quantity of bicycles in Taiwan declined, and the export quantity remained stable after 2000 (see "Fig. 3"). It can be seen from "Fig. 3" and "Fig. 4" that the unit price and the total amount of bicycle export have increased significantly, which is the result of Taiwan's bicycle industry cluster's pursuit of product differentiation and high value-added upgrade.

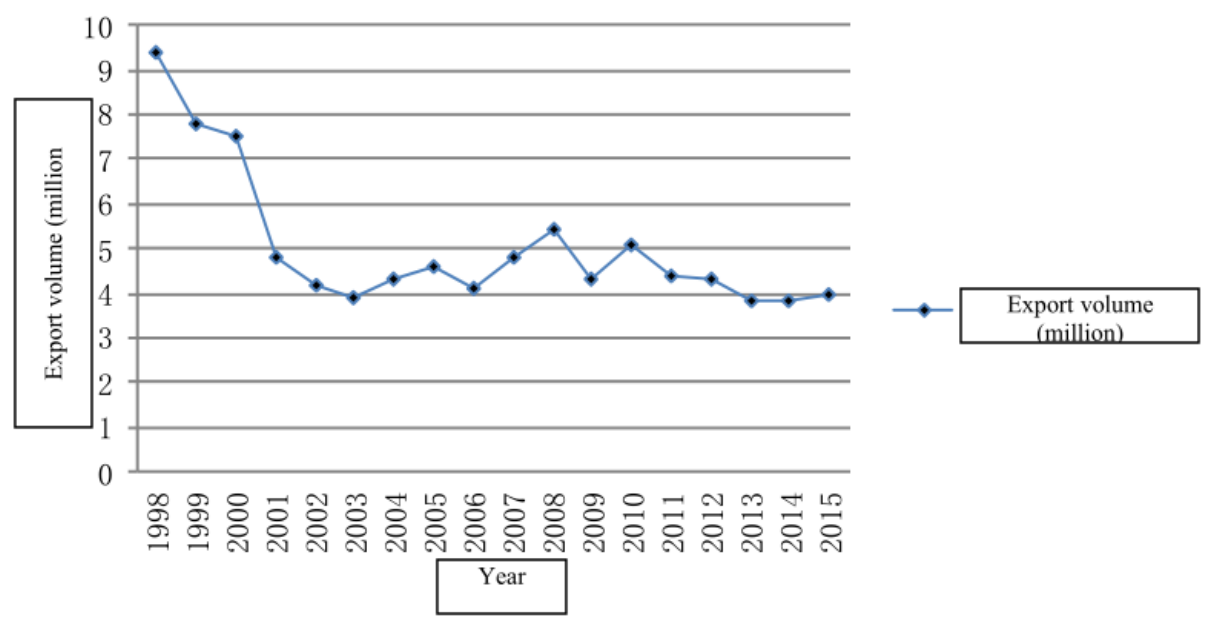

Fig. 3. Statistics on the number of bicycles exported in Taiwan from 1998 to 2015.

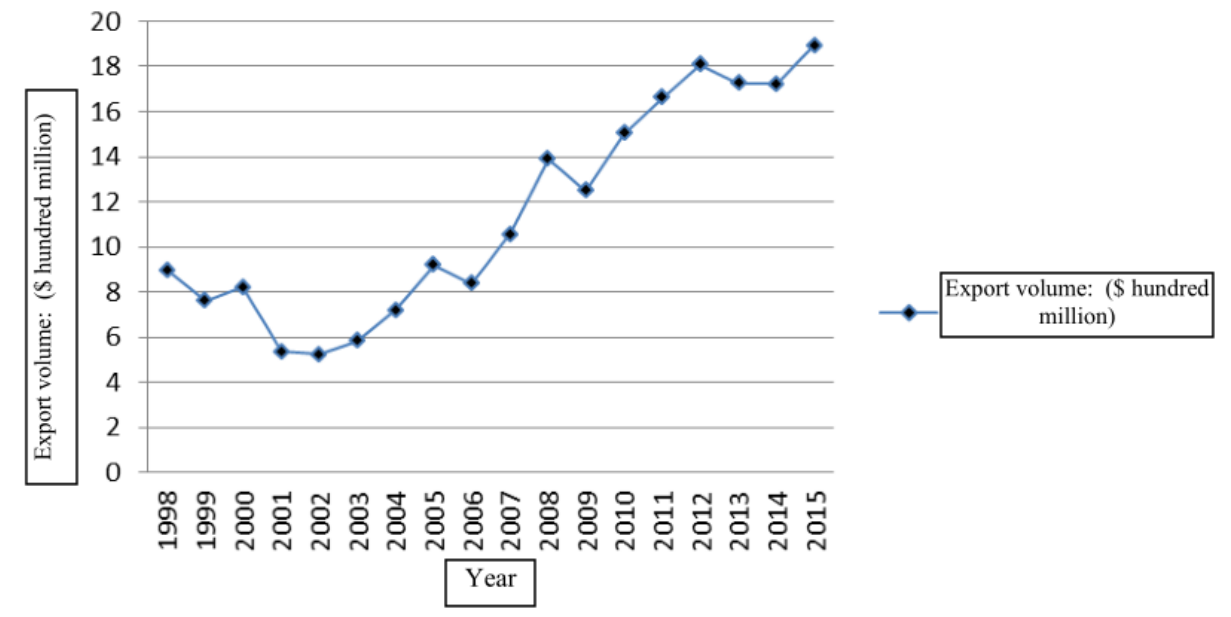

Fig. 4. Statistics on the export value of finished bicycles in Taiwan from 1998 to 2015. 


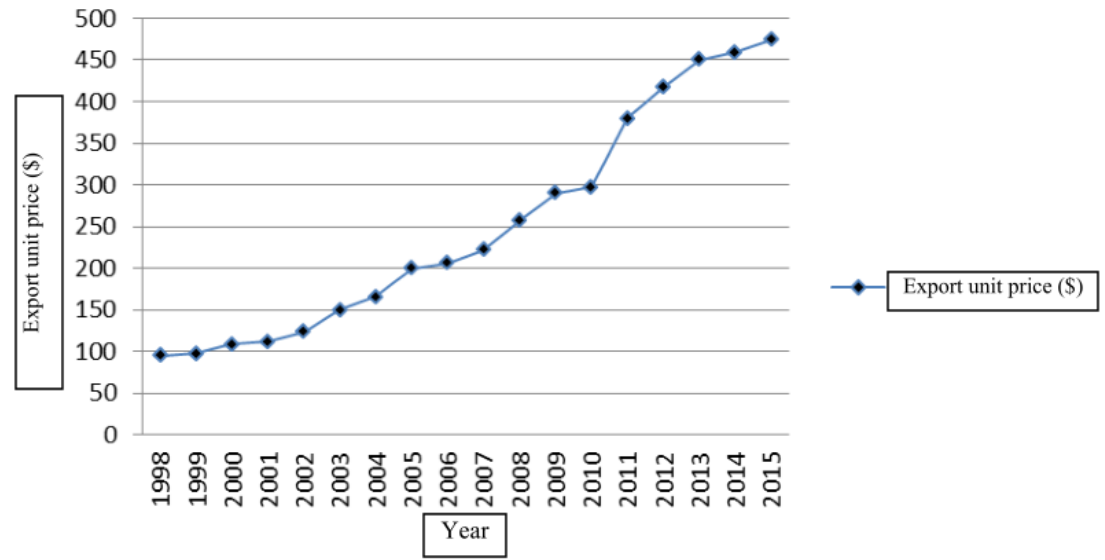

Fig. 5. Average unit price of finished vehicle export in Taiwan bicycle industry from 1998 to 2015 .

\section{The adjustment stage of Taiwan's bicycle industry cluster}

Bike-sharing is a product of the sharing economy concept, which relies on the development of Internet technology and smart phones. Allowing users to ride anytime and anywhere by scanning the QR code, it is characterized by convenience, convenience, safety, and fashion and sharing, and can greatly meet users' travel needs. It is an important innovation mode in the field of public transportation, and has injected scientific and technological genes into the traditional bicycle industry. In 2015, the concept of bike-sharing emerged, and bikesharing platforms "Mobike" and "Ofo" far surpassed all other similar services. The number of bicycles exported by Taiwan's bicycle industry to the mainland dropped by more than $20 \%$ in 2016 compared with 2015 , and the total number of bicycles exported to the mainland dropped by more than $55 \%$ from January to June in 2017 compared with the previous year (see "Table I"). The market share drops sharply and the performance continues to be depressed. Taiwan's bicycle industry is at a crossroads and facing new challenges. It is necessary to make timely industrial adjustment and think about the new industrial way out. Therefore, this paper believes that the bicycle industry cluster in Taiwan is in the adjustment stage, and different adjustment methods within the cluster will bring the new trend of the cluster, namely decline, transformation or upgrade. (Data source: official websites of Mobike and Ofo)

TABLE I. SUMMARY OF TAIWAN'S BICYCLE EXPORTS TO THE MAINLAND FROM JANUARY TO JUNE, 2014 TO 2017

\begin{tabular}{|c|c|c|c|c|}
\hline Year & $\mathbf{2 0 1 4}$ & $\mathbf{2 0 1 5}$ & $\mathbf{2 0 1 6}$ & $\begin{array}{c}\text { Jan.-June, } \\
\mathbf{2 0 1 7}\end{array}$ \\
\hline $\begin{array}{c}\text { Number of Bikes } \\
\begin{array}{c}\text { Exported from } \\
\text { Taiwan to the } \\
\text { Mainland }\end{array}\end{array}$ & 137,643 & 100,722 & 74,853 & 16,666 \\
\hline
\end{tabular}

\section{THE COPING STRATEGIES OF TAIWAN'S BICYCLE INDUSTRY CLUSTER FROM THE PERSPECTIVE OF SHARING ECONOMY}

Ruan Xiaodong (2015) [4] proposed that "sharing economy" endow people with two roles: consumer and owner, turning the ownership of products into the "use value" of products and the "network" formed by sharing economy will touch every corner of life. Shared bikes can exactly meet users' needs. Smart bikes with convenient actions can meet the short-distance travel demand of "the last kilometer", which conforms to people's living needs and is a successful application of the use value of sharing economy. The traditional view regards bicycles as private property for purchase, use and maintenance. Since the formation and evolution of the bicycle industry cluster in Taiwan, this concept has been deeply rooted in the value system. Therefore, under the development of shared bicycles, Taiwan has suffered a great impact and faced the challenge of market reshuffle.

The development of bike-sharing has accelerated the integration of resource chains in the upper, middle and lower reaches of the bicycle industry, dealing a devastating blow to low-end manufacturers. Bicycle manufacturers such as Forever and Pigeon have also received orders for mass production of shared bikes. This kind of production will not only dilute the profits of middle and low-end bicycle manufacturers, but also make small and medium-sized enterprises in the industry chain face elimination because they cannot get orders. At present, the core of the competition of Taiwan's bicycle industry cluster lies in high valueadded products and product differentiation. The export profits of complete bicycles in Europe and North America are huge, where the market share has not been occupied by shared bicycles. With the gradual deepening of bike-sharing in the international market, the sharing concept makes the market share of Taiwan's bicycle industry cluster in Europe and North America under potential threat, and the future development of 
the bicycle industry cluster will be more whirling. This is consistent with Christensen's explanation of the failure process of leading enterprises to face breakthrough innovation. Currently, bike-sharing is stealing the market of low-end manufacturers of the bicycle industry, and there is still huge profit space in the high-end segment of high added value and differentiation. However, if no changes, timely adjustments and upgrades are made according to market changes, this "pull in the northeast corner" will eventually drive leading enterprises out of the market, which requires Taiwan's bicycle industry cluster to be vigilant.

This paper argues that enterprises in clusters need to improve their organizational flexibility and change their business sales model according to market changes. The traditional sales channels are blocked by shared bikes, and the previous effective experience of enterprises cannot be applied. Therefore, it is necessary to integrate the "sharing concept" into bicycle marketing, shift from the product demand end of users to the use demand end, rethink the positioning, actively explore new needs of users, and enhance user experience. In addition, the bicycle industry in Taiwan needs to integrate government innovation resources, accelerate organizational change, enhance the organization's ability to respond flexibly to the market, and make use of the powerful recording and analysis function of Internet big data to make accurate judgment, so as to provide more professional services for customers, so as to carry out better strategic response. Finally, under the sharing economy model, enterprises need to make efforts to share their own value. For example, focusing on the difficulties faced by the initial promotion of shared bikes, they can be committed to the intelligent upgrading and transformation of certain retail components such as smart locks, chains, tires, etc. of shared bikes, forming manufacturing standards for shared bikes, and striving for more orders. Or they can continue to increase sales of e-bikes into the sales concept of sharing and join the sharing trend.

\section{CONCLUSION}

This paper divides the evolution process of industrial cluster into five stages, that is, potential stage, emerging stage, expansion stage, maturity stage and adjustment stage. The characteristics of each evolution stage are summarized in detail. In the adjustment stage, according to different coping modes, industrial clusters will go to different results, decline, transfer or upgrade. Based on the theory of industrial upgrading, this paper summarizes the upgrading mode of industrial cluster from lower stage to higher stage. They are production promotion, quality promotion, brand upgrading, brand differentiation upgrading, organizational response and sales model upgrading.
This paper explains this model based on the evolution history of bicycle industry cluster in Taiwan The development course of Taiwan's bicycle industry cluster is exactly in line with the cluster evolution and upgrading study in this paper, but the evolution models of different industries may be different, and the accuracy of the model needs to be further confirmed. The "sharing economy" turns owning a product into owning its "use value". And the shared bikes meet users' needs, which is a successful application of the concept of sharing economy. It is proposed that the transformation and upgrading of Taiwan's bicycle industry cluster under the sharing economy model depends on the change of marketing model and the strategy of flexible response of the organization.

In next stage, quantitative and empirical studies can be conducted on cluster evolution and upgrade path model. Whether the successful evolution history of Taiwan's bicycle industry cluster can be sustained under the concept of sharing economy and how to realize new development by integrating the traditional industry and sharing concept will be the focus of future research.

\section{References}

[1] Bergman. E. M and Feser. E. J. Industrial and Regional Clusters: Concepts and Comparative Applications [J]. Regional Research Institute, West Virginal University, 1999.

[2] Shao Yunfei, Li Li, Fan Qunlin. Study on the Life Cycle Evolution Stages of Industrial Cluster - a Case Study of Taiwan Bicycle Industrial Cluster [C]// 2010. (in Chinese)

[3] Mao Yunshi, Lin Xiaoru, Li Yuhui. Research on the Upgrading of Labor-Intensive Industries - a Case Study of the Overall Upgrading of Taiwan's Bicycle Industry and Its Competition and Cooperation Mechanism [J]. Academic Research, 2011(6): 63-70. (in Chinese)

[4] Ruan Xiaodong. The Era of Sharing Economy Comes [J] Economy Research Guide, 2015(4): 54-59. (in Chinese)

[5] Clayton M. Christensen, Wu Qianlong. The Innovator's Dilemma [M]. Jiangsu People's Publishing, Ltd., 2001.

[6] Mao Yunshi, Lin Xiaoru, Li Yuhui. A Study on the Upgrading of Labor-intensive Industries — Take the Overall Upgrade and Cooperation Mechanism of Taiwan Bicycle Industry as an Example [J]. Academic Research, 2011(6):63-70. (in Chinese)

[7] Ruan Xiaodong. The Era of Sharing Economy is Coming [J]. New Economy Weekly, 2015(4):54-59. (in Chinese)

[8] Clayton Christensen, translated by $\mathrm{Wu}$ Qianlong. The Innovator's Dilemma [M]. Jiangsu People's Publishing House, 2001. (in Chinese) 